\title{
Design of automatic control system of multi-parameters in engine room in the oil tanker based on PLC technology
}

\author{
Zou Yong-dong ${ }^{1, a}$, Zhu Fa-xin ${ }^{1, b}$ and Li Yu-le $e^{1, c}$ \\ ${ }^{1}$ Haida South Road, Lincheng Changzhi Island,Zhoushan, Zhejiang, 316022 P.R.China \\ ${ }^{2}$ Haida South Road, Lincheng Changzhi Island,Zhoushan, Zhejiang, 316022 P.R.China \\ ${ }^{3}$ Haida South Road, Lincheng Changzhi Island,Zhoushan, Zhejiang, 316022 P.R.China \\ azydong23@126.com, bzhufax7758@163.com, ${ }^{\mathrm{c}} 704952772 @ q q . c o m$
}

Keywords: Technique of PLC; multi-parameter; automatic control; ventilation system; cabin;engine.

\begin{abstract}
For the current shortcomings and deficiencies existing in tanker cabin, such as high temperature,high humidity,gas concentration,and does not automatically be controlled,this article considers from the tanker cabin design requirements and the necessity of it's multi-parameters control. On the basis of the existing cabin ventilation system on the tanker,uses PLC technology to design a multi-parameter tanker cabin automatic control system,and introduces the principle of this automatic control system by composition,temperature,humidity and gas concentration and other parameters. Finally,the feasibility of this system was analyzed from the structure,technology, economic and other aspects.

\section{Introduction}

Because of the small volume,low energy consumption and strong anti-jamming capability of the PLC (Programmable Logic Controller).It comes with the hardware fault detection function, when the fault occurs that can alert information within a few microseconds and soon,So,It has been used widely in the field of marine equipment automation.[1,2]Such as the ship main engine remote control, the diesel engine power plant monitoring alarm , engineering monitoring and trend analysis technology, ship fault diagnosis, etc.[2]

Engine room is the power center in the ship, the cabin multi-parameter change directly affect the operation condition of the engine room equipment and the turbine working conditions. In order to solve the currently existing in engine room temperature and high gas concentration and humidity can't automatically control faults,improved the automation of engine room. This article embarks from the engine room automation system design requirements, design a set of engine room ventilation system based the cabin multi-parameter automatic control system.
\end{abstract}

\section{Overview of engine room in the oil tanker}

\subsection{Engine room ventilation system in the oil tanker}

The engine room ventilation system including the type of ventilator, ventilation pipeline, ventilation way, return air shaft, downcast shaft, and other relevant devices. Engine room ventilation system according to the different ventilation power, can be divided into natural ventilation and mechanical ventilation system.[3]mechanical operation of the mechanical ventilation is due to the formation pressure inside the outside air into the engine room ventilation form; And the natural ventilation is wind formation of the wind pressure outside the engine room and engine room air temperature difference caused by hot pressing both inside and outside, to realize the cabin air exchange a form of ventilation.[4]The mechanical ventilation system and full fresh air system, circulation cooling plus fresh air system and jet ventilation system.

\section{2The necessity of multi-parameter controlling cabin engine room}

\section{1) Temperature control}

The research data suggest that the best operating environment temperature is 15 degrees to 20 degrees. Nevertheless in the cabin engine room, temperature is far above the 20 degrees because diesel engines, boilers and the like release heat continuously to the room whose temperature will go up.[4]In the high temperature environment, the human body radiate the heat by evaporation, in the perspiration human loses large amongst of body salt so that blood pressure drops, or worse yet, it 
places extra load on the heart and raise the risk of disease among engineer. And the high temperature has effects on human neural activity and coordination. Thus engine room's temperature level is ensured by thermal control system in order to ensure engineer have a good working environment.

\section{2) Humidity control}

With the engine room's humidity changes, the precision and sensibility of instrument will change too. When the environment humidity is above or below the operating humidity, the instrument can't work and even damaged.[5]

\section{3) Oil-gas concentration control}

The engine room will inevitably leaks of oil vapor due to the cleats which is filled with fuels, the burning of combustion equipment, the leaking of pipeline and so on. On these accounts, fires and explosions may occur when the Oil-gas concentration reaches a certain degree, causing major losses and a direct threat to the cabin and the life safety of the crews. Consequently, we must control the Oil-gas concentration in the engine room to avoid the occurrence of fires and explosions.

\section{The analysis about demands of the design with engine room automation system of cabins}

According to the "Classification Rules of Steel Sea-going Vessel” (compiled in 2014), the followings are the primary demands which is asked when designing engine room automation system.

\section{1)Sensor}

The sensor is bound to be capable of working steadily and chronically with appropriate precision and sensitivity. It's required to get accustomed to the working conditions with a proper position after which it can guarantee the accuracy of the parameter measured, besides, there should be an easy dismount for convenience.

\section{2)Controlling System}

The controlling system is supposed to function effectively, continues and reliably. What's more, the requirement of the humidity is that the concerned humidity is from $92 \%$ to $98 \%$ when the temperature is under 45 degrees while on the other range; it's between $67 \%$ and $73 \%$.

\section{3)Alarm system}

The key point about the alarm system is that it can make an alarm in the ECR (Engine Control Room) or on the position where the equipment is placed. Ability of system diagnostics and prognosis is really needed so that it can make these faults happening during the running independent. [6]

\section{Design of automatic control system of multi-parameters in engine room in the oil tanker}

\section{based on PLC technology}

\subsection{Automatic controlling principles of temperature in the engine room}

The system is mainly of temperature sensor, A/D converter, PLC, D/A converter, alarms, ventilator, air-duct, an damper and other components (such as shown in Fig. 1).The change of the cabin engine temperature monitored by temperature sensor 1-6 and transfer to the A/D converter real-time,then the A/D converter conversion transfer to PLC and ECR,finally indicated in instrument display screens.PLC,will receive the date and compare with settled value one by one,issue the instruction that increase the sensor corresponding to the damper angel,when two or less of the date exceeds the settled value; when more than two of the date exceeds the settled value,issue the instruction that VFD (Variable-frequency Drive) in order to increase the speed of the machine;when the received date was incomplete,bigger than the maximum of settled value,a sound,light alarm open,and doesn't affect the execution of other instruction. The instruction act on damper or ventilator adjust the blowing rate in cabin,which from PLC will be converted to analog signals by D/A converter. 


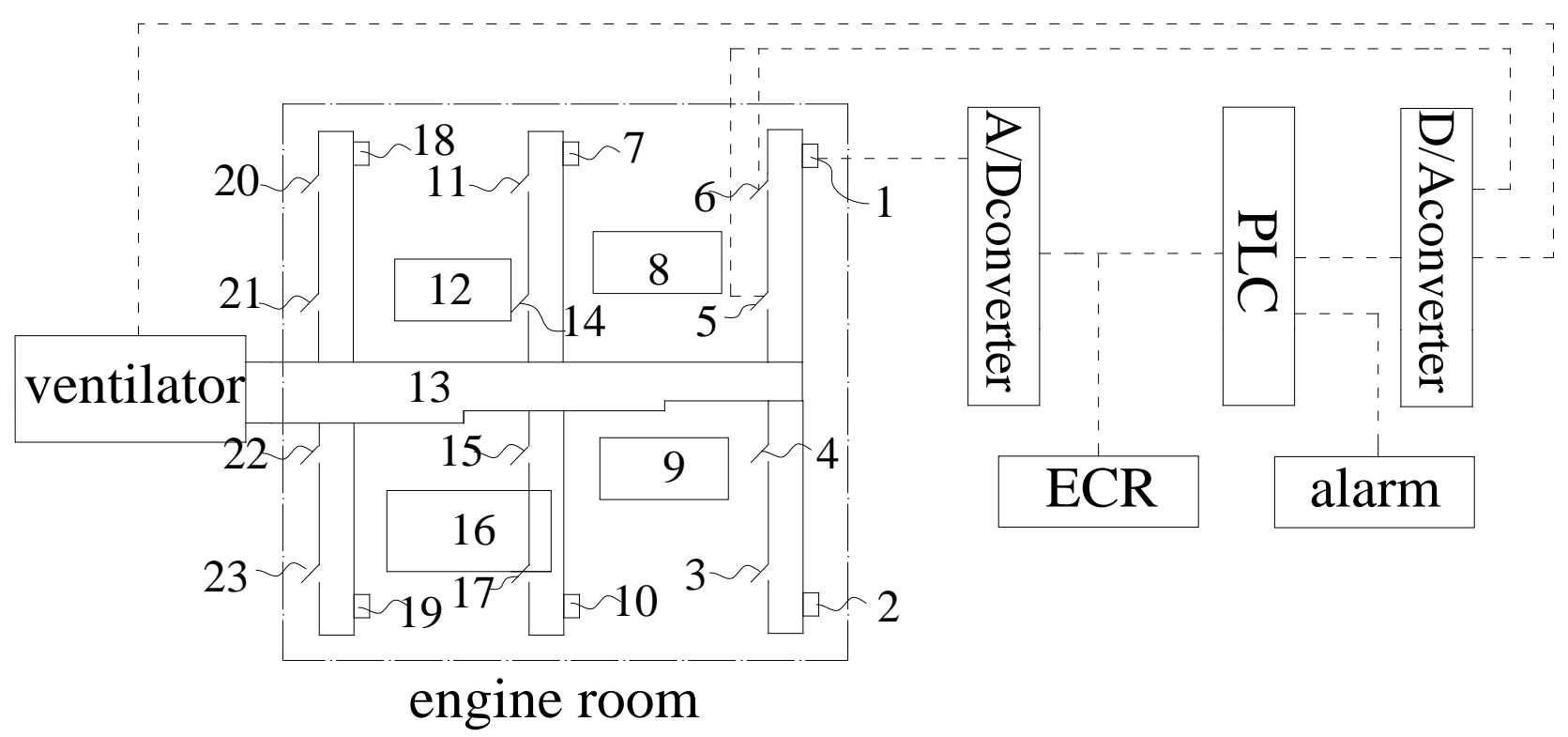

1 ,2,7,10,18,19-temperature sensor; 3,4,5,6,11,14,15,17,20,21,22,23-damper;

8,9-diesel generator engine ; 12-boiler; 13-vent manifold; 16-main engine.

Fig. 1 Design of automatic control system of multi-parameters in engine room in the oil tanker.

\subsection{Some automatic controlling principles of other parameters in the engine room}

\section{1) Oil-gas concentration}

As for the automatic controlling of Oil-gas concentration in the engine room, just turn the temperature sensor to a Oil-gas concentration sensor in Fig 1, the principle, which is equal to the temperature controlling, is using the ventilation system in the cabin engine room to scavenging the oil vapor in order that it can control the Oil-gas concentration in the engine room automatically.

\section{2)Humidity}

The automatic control of the cabin engine humidity is relatively complex. Because of the uncertainty of the outside air humidity, ultrasonic humidifier and wheel dehumidifier should be settled up in front of the engine room ventilation manifold, to change the humidity of the air entering the engine. Outside air goes into the ventilation manifold under the mechanical action of ventilator, and then under the effect of wheel dehumidifier for air dehumidify after entering the engine, mixed with the cabin air, ventilation, to reduce the role of the cabin air humidity; When the engine air humidity measured by humidity sensor is lower than the settled value, PLC gives ventilator instruction that VFD and the ultrasonic humidifier working instructions, air after ultrasonic humidifier function goes into the engine, and increase the role of the engine air humidity.

\subsection{Main part}

\section{1)PLC}

Adopt computer control technology of PLC, by writing program implementation control and protection functions; realize the automatic control of cabin engine room multi-parameter. [7]PLC programming is as most of the design method of software engineer, the general design process diagram available. Automatic temperature control of PLC program flow diagram (such as shown in Fig. 2): 


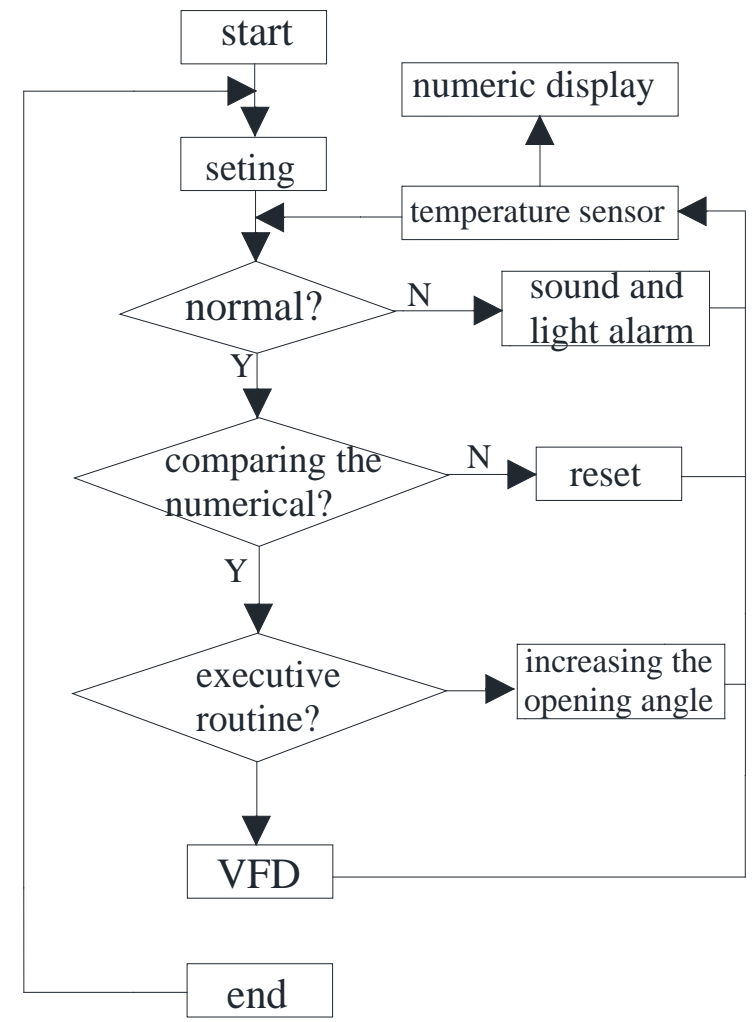

Fig.2 Automatic temperature control of PLC program flow diagram.

\section{2)Ultrasonic humidifier}

Considering the technology of humidification and energy saving effect, the system uses the ultrasonic humidifier. Concrete working principle is: through ultrasonic high frequency oscillation, in the role of change to one, the water mist into 1-5um water mist particles, heat exchange with the air flow to achieve the purpose of humidification .[8]

\section{3)Wheel dehumidifier}

Wheel dehumidifier dehumidify principle is: the adsorption rotary table driven by a shaft rotation at low speed, half in the treatment of the area to absorb water molecules in the air, the other half in the blanket to heat the absorption of water molecules, the process cycle, and its advantages are high efficiency, large amount of dehumidify.

\section{Feasibility analysis}

\subsection{Structure}

Currently,there are no experts studying the automatic control about of multi-parameters in engine room in the oil tanker.Therefore,the new system has greet superior,The advantages in structure are as following:

1)Compared with the of the existing cabin ventilation system on the tanker, the new system is more simple with several master device, such us sensors,A/D converter ,PLC,D/A converter , alarms.

2)For the purpose of improving the accuracy of the sensor, we set it behind ventilation pipeline . Of course, we can not only build it in new oil tanker, but also the existing of the existing cabin ventilation system on the tanker.

3)Considering the broken and measuring of these devices, the new system has alarms, which can satisfy the demands of automatic in the oil tanker.

\subsection{Technology}

We know that PLC has been the most skillful automation technology in the fields of oil tanker. In order to achieve the auto-control of multi-parameters in engine room in the oil tanker,the technical scheme adopt is as following: The machine sends the data the sensor gets to compare with the settled, outputting execution instructions, after that, we get the goal of controlling multi-parameters. The structure of the system is simple and convenient to install. It increases the oil tanker's automation level as well as easing the burden for engineer. 


\subsection{Economy}

Even though engine room automated ventilation system in the oil tanker,needs more sensors and alarms, the cost it`s equal to what the current system needs. When the new system is combined with the PLC, it reduces a waste of energy as well as the working intensity, improving automated level and efficiency of ventilation. During the early period, it just needs small initial investment, which is content with requirement of economy.

\section{Conclusions}

The system we designed is tally with the demands of engine room system and it can reduce what the engineer need to do workload. Most importantly, increase efficiency of ventilation. At the same time, it provides us with some references to make unmanned machinery space true.

The research about design of automatic control system of multi-parameters in engine room in the oil tanker is still on the way, failed to on the professional simulation software simulation whose reliability has not been tested,Also did not consider the cabin several parameters influence each other.Therefore, the further study we will do is to check out how it works on earth under those factors above.

\section{References}

[1] Fan Yong-sheng, Wang-min, Electrical control and PLC application, second ed.The summary of PLC, China Power Press, Beijing, (2007), p. 113-124.

[2] Wang Jin-guang, Tu xing-jian, Li Ri-fa, Analyze the status of ship automation technology, J.Journal of information science and technology. 12 (2014) 55-55.

[3] Liang Yan-chao, A ship engine room ventilation system simulation analysis and optimization design, D.Shanghai Jiao Tong University (2011)

[4] Yu Xue-xing, Sun Pei-ting, Xia Zhi-fa, etc, Of the ship engine room natural ventilation, J.Journal of dalian maritime university, natural science edition.

[5] He Wei-jian,Ship engine room ventilation velocity field temperature field numerical simulation , D.Dalian maritime university(2005)

[6] CCS, Classification Rules of Steel Sea-going Vessel.Article 7 automation system,S.(2014)

[7] Zhao-yan,The development of the Marine engine room equipment operation data acquisition system, D.Jimei university(2013)

[8] Sun-ying, Sun Yan-xiu, The introduction and selection of analysis of air conditioning with humidifier, J.Journal of refrigeration and air conditioning and electric machinery. 31,3. (2010) 